$$
\begin{gathered}
\text { RAFAEL GOMES DITTERICH } \\
\text { DAIANA KLOH KHALAF } \\
\text { LUÍS FELIPE FERRO } \\
\text { REGINA MARIA FERREIRA LANG } \\
\text { ERILDO VICENTE MÜLLER } \\
\text { GIOVANI MARINO FAVERO } \\
\text { ORGANIZADORES }
\end{gathered}
$$

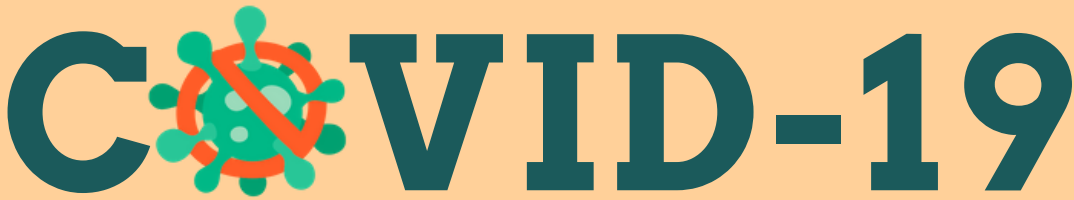

Orientações à população em situação de rua

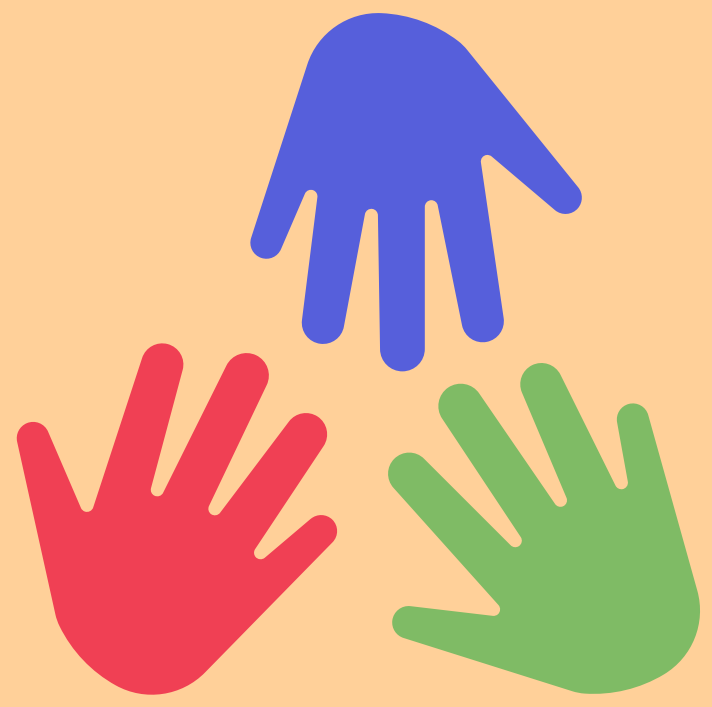




\section{GOVERNO DO ESTADO DO PARANÁ \\ Governador}

Carlos Massa Ratinho Júnior

Vice-governador

Darci Piana

Superintendência Geral de Ciência, Tecnologia e Ensino Superior

Aldo Nelson Bona

UNIVERSIDADE ESTADUAL DE PONTA GROSSA

Reitor

Miguel Sanches Neto

Vice-reitor

Everson Augusto Krum

UNIVERSIDADE FEDERAL DO PARANÁ

Diretor do Setor de Ciências da Saúde

Nelson Luis Barbosa Rebellato

Vice-Diretor do Setor de Ciências da Saúde

Edison Luiz Almeida Tizzo†

\section{Colaboradores}

Amanda Khetleen Gusso

Bruna Menezes Mincov

Caique Lima Sette Franzoloso

Carolina Batista de Souza

Flávia Castro Rosa

Giovani Pereira

Isabela Cristina Santos Freire de Paula

Jhenifer Geisa Burnagui

Karoline Fernanda Zamboni Bonan

Larissa Guil

Victória lacono Casarin Olivo
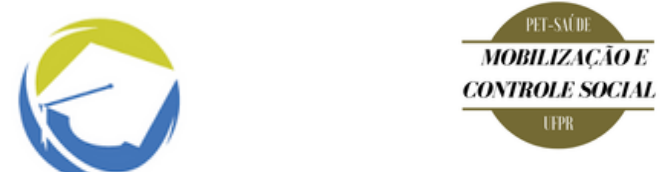

CONTROLE SOCIAL

IIIR

PET-Saúde

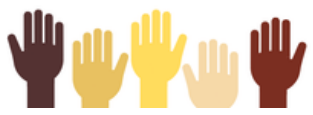




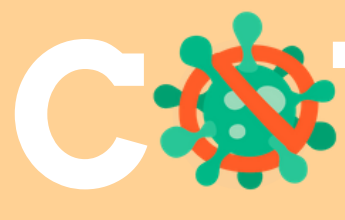

$$
\begin{aligned}
& \text { Orientações à } \\
& \text { população em } \\
& \text { situação de rua }
\end{aligned}
$$




\title{
PROEX UEPG
}

\section{Equipe Editorial}

\section{Revisão de língua portuguesa \\ Emilson Richard Werner}

\author{
Arte \\ Amanda Khetleen Gusso \\ Carolina Batista de Souza \\ Larissa Guil
}

Diagramação

Andressa Marcondes

Apoio

Editora UEPG

C873

COVID-19: orientações à população em situação de rua [livro eletrônico]/ Rafael Gomes Ditterich et al. (org.). Ponta Grossa: UEPG/PROEX, 2020.

47f.; E-book PDF

ISBN: 978-65-86967-08-1

DOI: $10.5212 / 86967-08-1$

1. Corona vírus. 2. COVID-19- sintomas. 3. Prevenção. 4. População de rua. I. Ditterich, Rafael Gomes et al. (Org.). II. T.

CDD: 618.2

Ficha Catalográfica elaborada por Maria Luzia F. B. dos Santos - CRB9/986 


\section{APRESENTACÃO}

Diante da atual situação imposta a nossa comunidade pela COVID-19, vários desafios são apresentados para garantir o cuidado de todos os cidadãos brasileiros. Este material, produzido pela parceria entre Universidade

Estadual de Ponta Grossa (UEPG) e a Universidade Federal do Paraná (UFPR), em conjunto com o Programa de Educação pelo Trabalho para a Saúde (PET-Saúde/ Interprofissionalidade) - Grupo Educação Popular, Mobilização e Controle Social na Saúde, procura oferecer informações acessíveis e confiáveis à população em situação de rua, apresentando dados sobre algumas das possíveis formas de cuidado, prevenção e apoio para o enfrentamento dos impactos da pandemia de COVID-19.

Esperamos que esta cartilha colabore para que diferentes pessoas em situação de rua possam ser cuidadas e protegidas! 

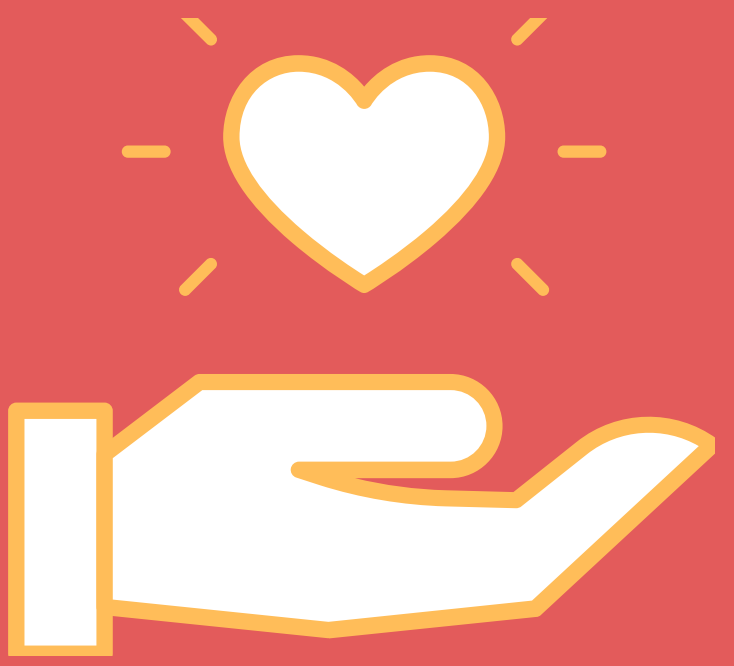

$$
\begin{gathered}
\text { ESTA CARTILHA } \\
\text { PRETENDE TIRAR } \\
\text { DÚVIDAS DA } \\
\text { POPULAÇÃO EM } \\
\text { SITUAÇÃO DE RUA } \\
\text { EM RELAÇÃO Á } \\
\text { COVID-19, DOENÇA } \\
\text { CAUSADA PELO } \\
\text { CORONAVÍRUS. }
\end{gathered}
$$




\section{O QUEÉ A COVID-19?}

É uma doença, causada por um vírus, que pode levar a problemas respiratórios.

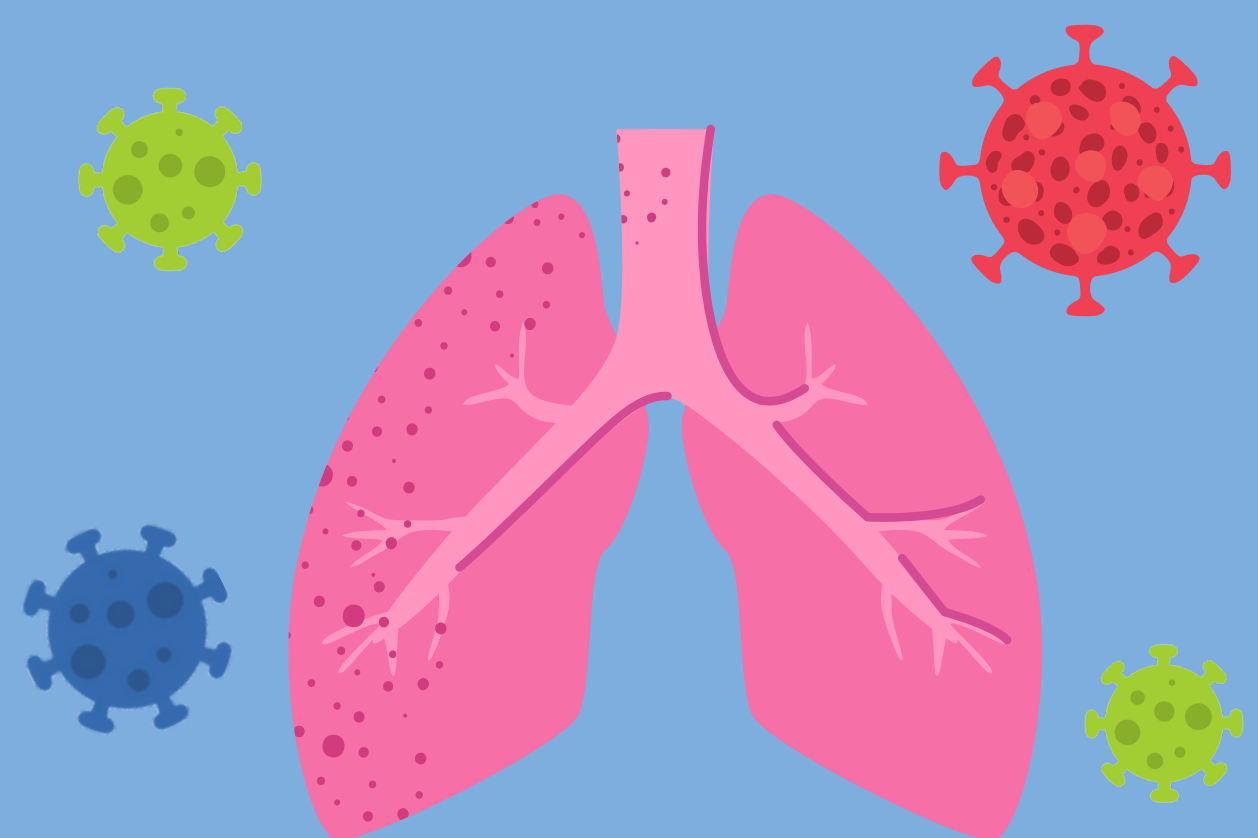




\section{O QUE CAUSA?}

Uma infecção pelo vírus que afeta o sistema respiratório.

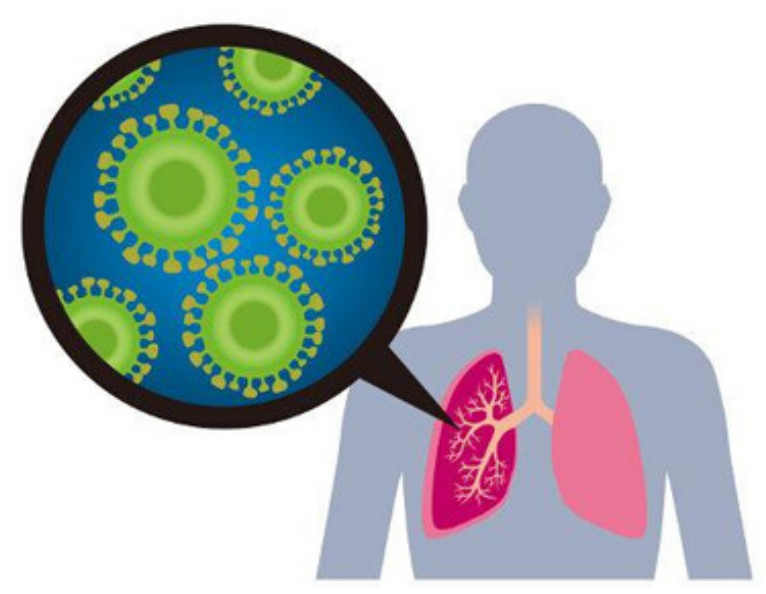

Ela pode ser confundida com gripe ou resfriado. 


\section{A COVID-19 é uma doença transmitida com muita facilidade.}
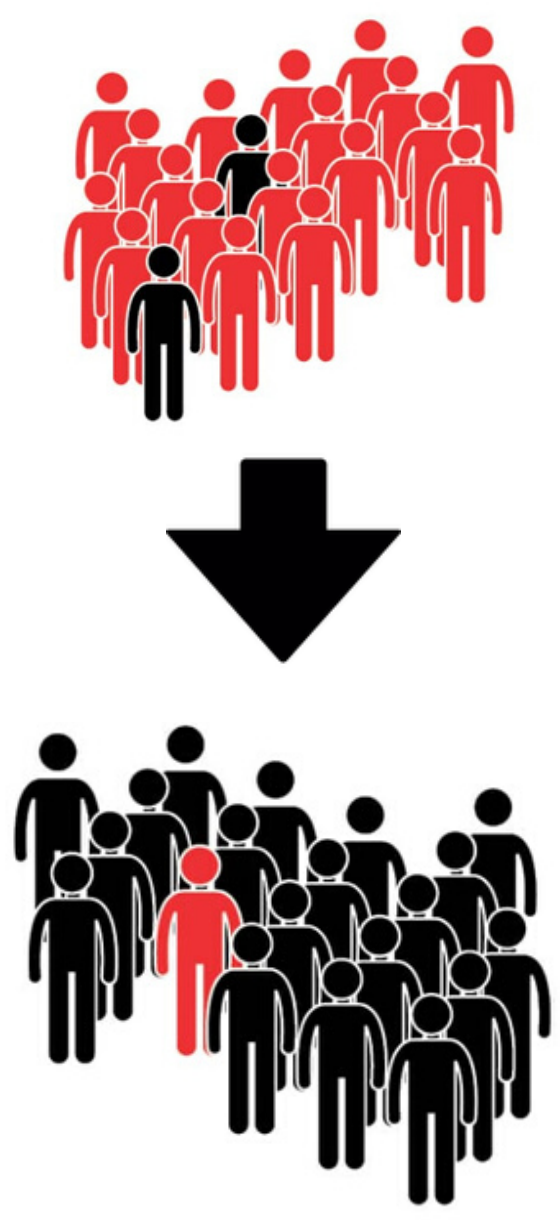


\section{As gotículas que}

saem com o espirro ou com a tosse podem contaminar objetos e superfícies, por exemplo o seu cobertor.
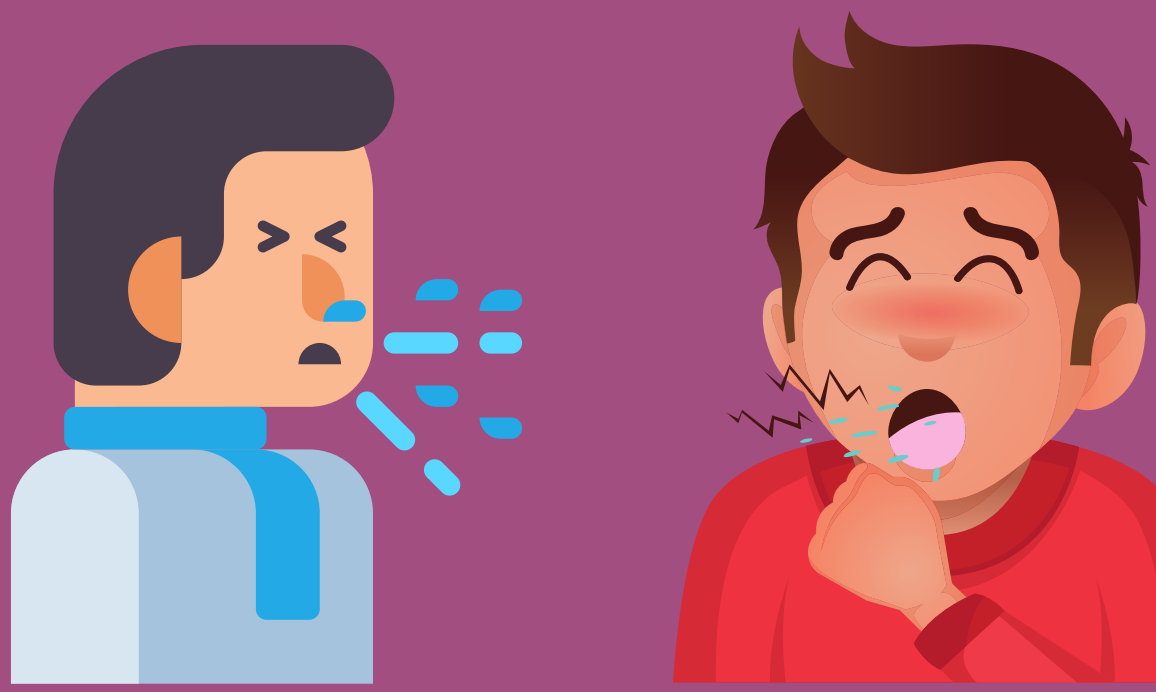


\section{VOCÊ PODE PEGAR}

A COVID-19

QUANDO

TOCAR

SUPERFÍCIES

OU OBJETOS

CONTAMINADOS

E DEPOIS TOCAR

OS SEUS OLHOS,

NARIZ

OU BOCA. 
Você também pode pegar a COVID-19 quando uma pessoa infectada tossir ou espirrar perto de você!

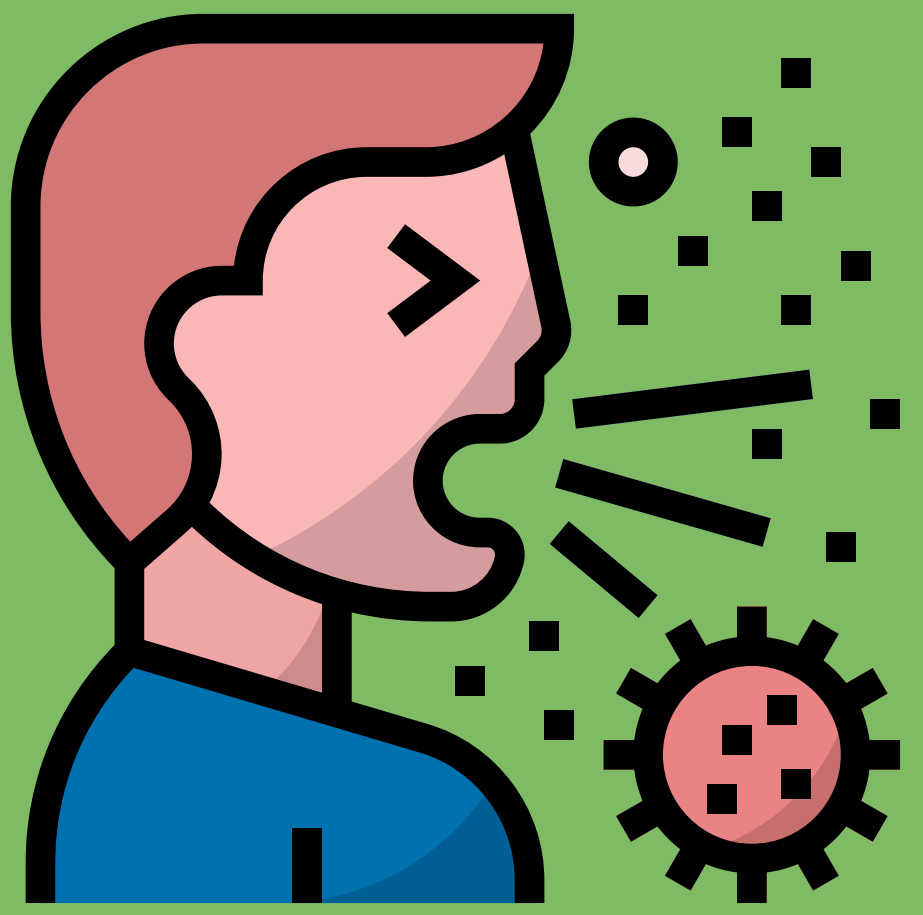




\section{Por isso, ficar próximo}

\section{a outras pessoas é \\ arriscado neste}

momento.

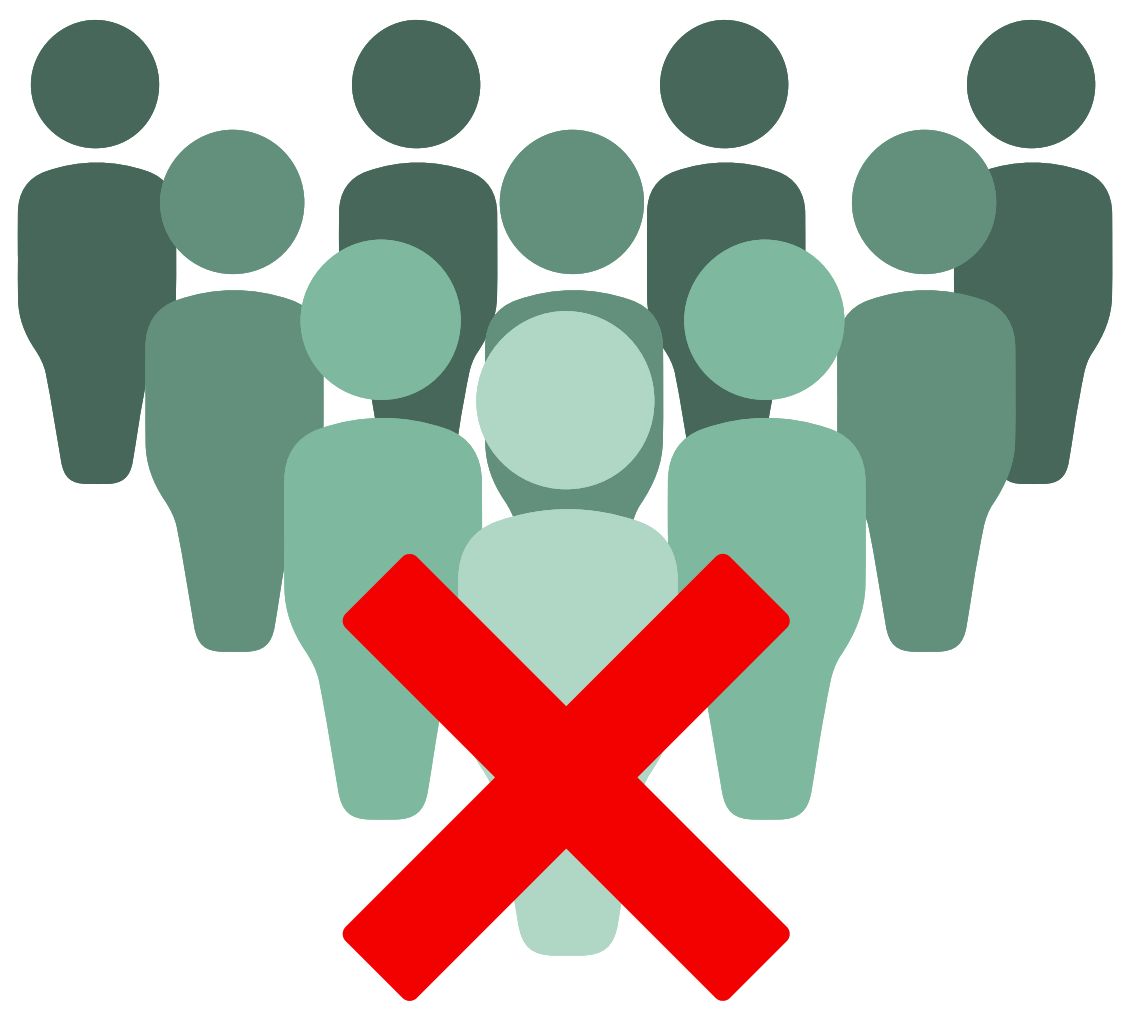




\section{SINAIS E SINTOMAS}

Os sintomas são

parecidos aos de

uma gripe comum.

Geralmente, é uma doença leve ou moderada, mas em casos graves pode até levar à MORTE! 


\section{SINAIS E SITOMAS}

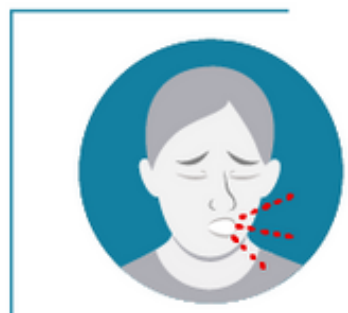

Tosse

\section{Mais comuns}

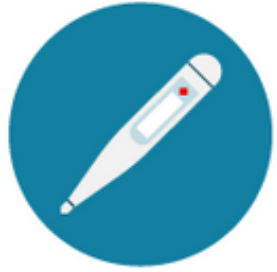

Febre

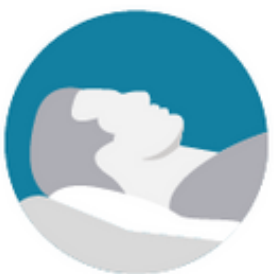

Fadiga

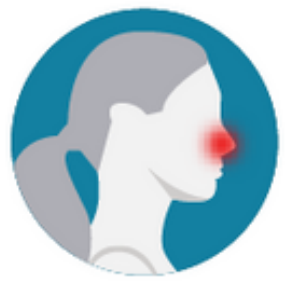

Congestão nasal

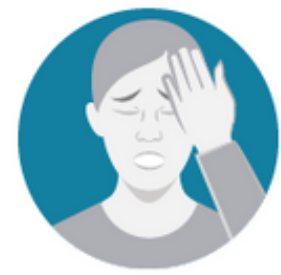

Cansaço

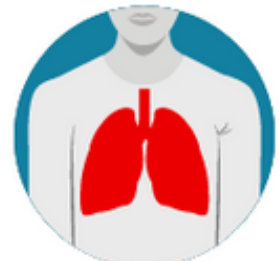

Dificuldade de respirar**

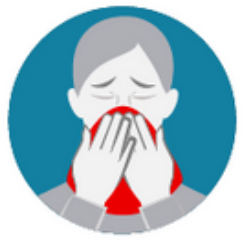

Coriza
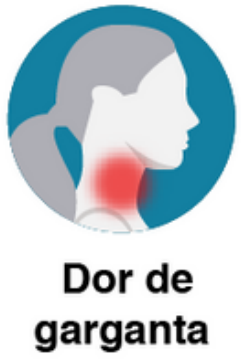

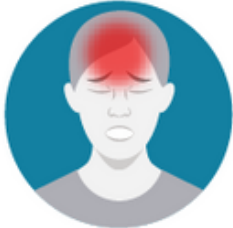

Dor de cabeça

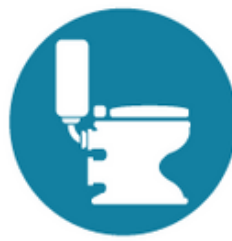

Diarreia

fonte: Ravagnani e Ramos (2020) 


\section{É possível pegar a \\ COVID-19 de uma pessoa}

que não apresenta sintomas?
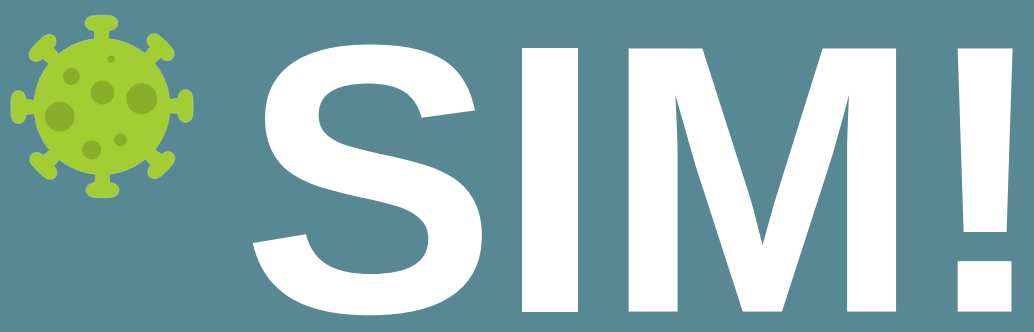

\section{Por isso, DEVEMOS}

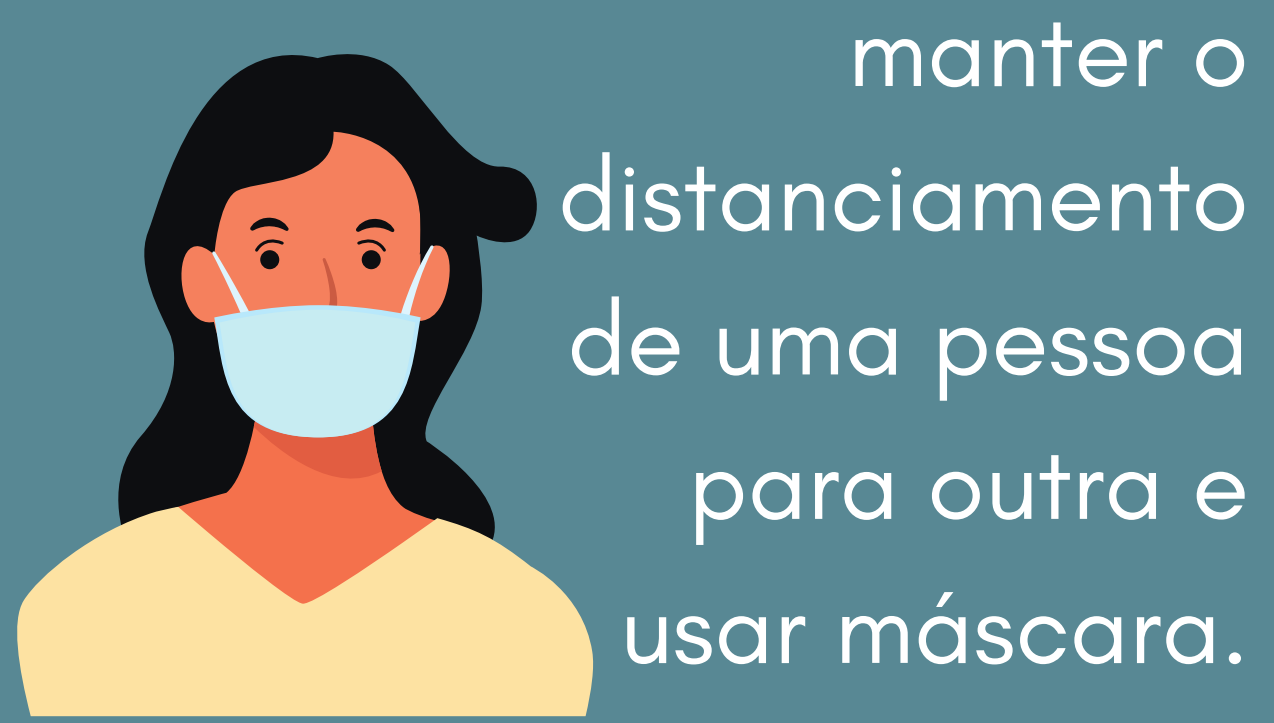




\section{GRUPOS DE RISCO}

Se você apresenta alguma das condições abaixo, o cuidado deve ser maior.

A pessoa que pertence aos grupos de risco deve tomar ainda mais cuidado e ficar atenta no caso do aparecimento de qualquer sintoma, pois a doença pode ser mais grave.

- Pessoas com mais de 60 anos;

- Pessoas que têm imunidade baixa (HIV/Aids, câncer);

- Pessoas com doenças crônicas (pressão alta, obesidade, diabetes, problema no coração);

- Pessoas com doenças pulmonares (asma, bronquite);
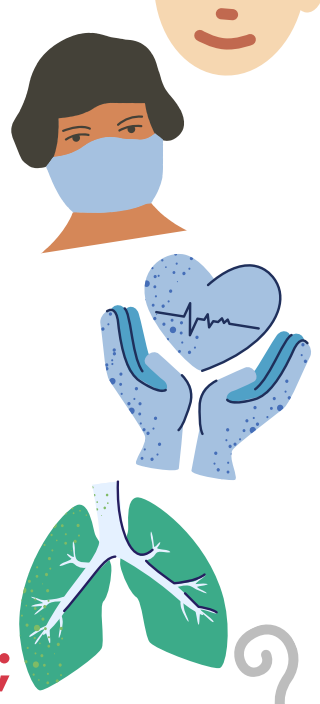

- Pessoas que são fumantes ou usuárias de drogas;

- Gestantes. 


\section{QUANDO EU DEVO PROCURAR AJUDA?}

Quando apresentar:

- Febre persistente;

- Dificuldade para respirar;

- Vômito persistente;

- Dor abdominal severa;

- Sangue nas fezes.

\section{UBS}

Unidade Básica de Saúde

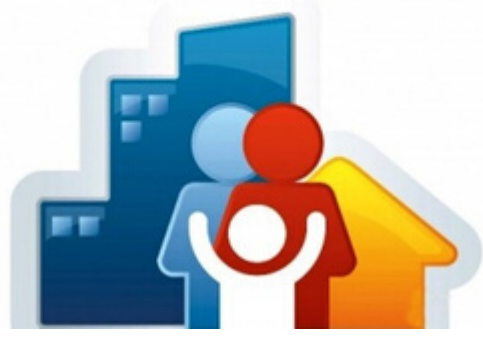

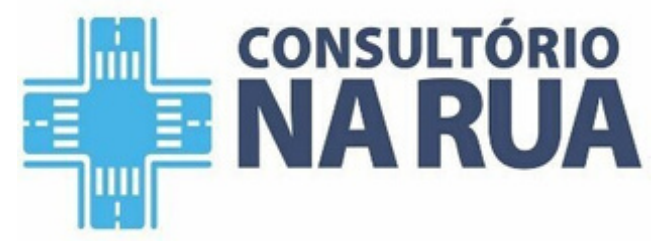

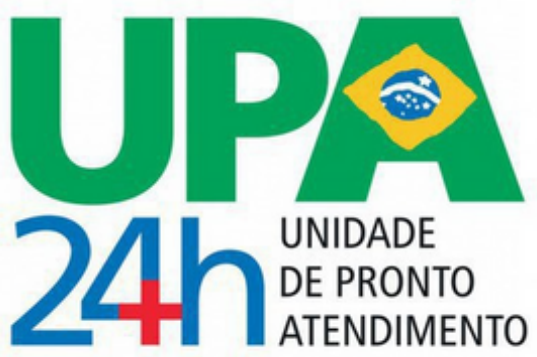


Além de buscar os serviços de saúde, quanto tempo devo ficar em isolamento social após o desaparecimento
dos sintomas?

\section{TENTE FICAR LONGE DE OUTRAS}

\section{PESSOAS POR, PELO MENOS, 14}

\section{DIAS E SEMPRE USAR MÁSCARA.}




\section{COMO SE PREVENIR?}

Manter distância de outras pessoas e evitar lugares com muita gente.
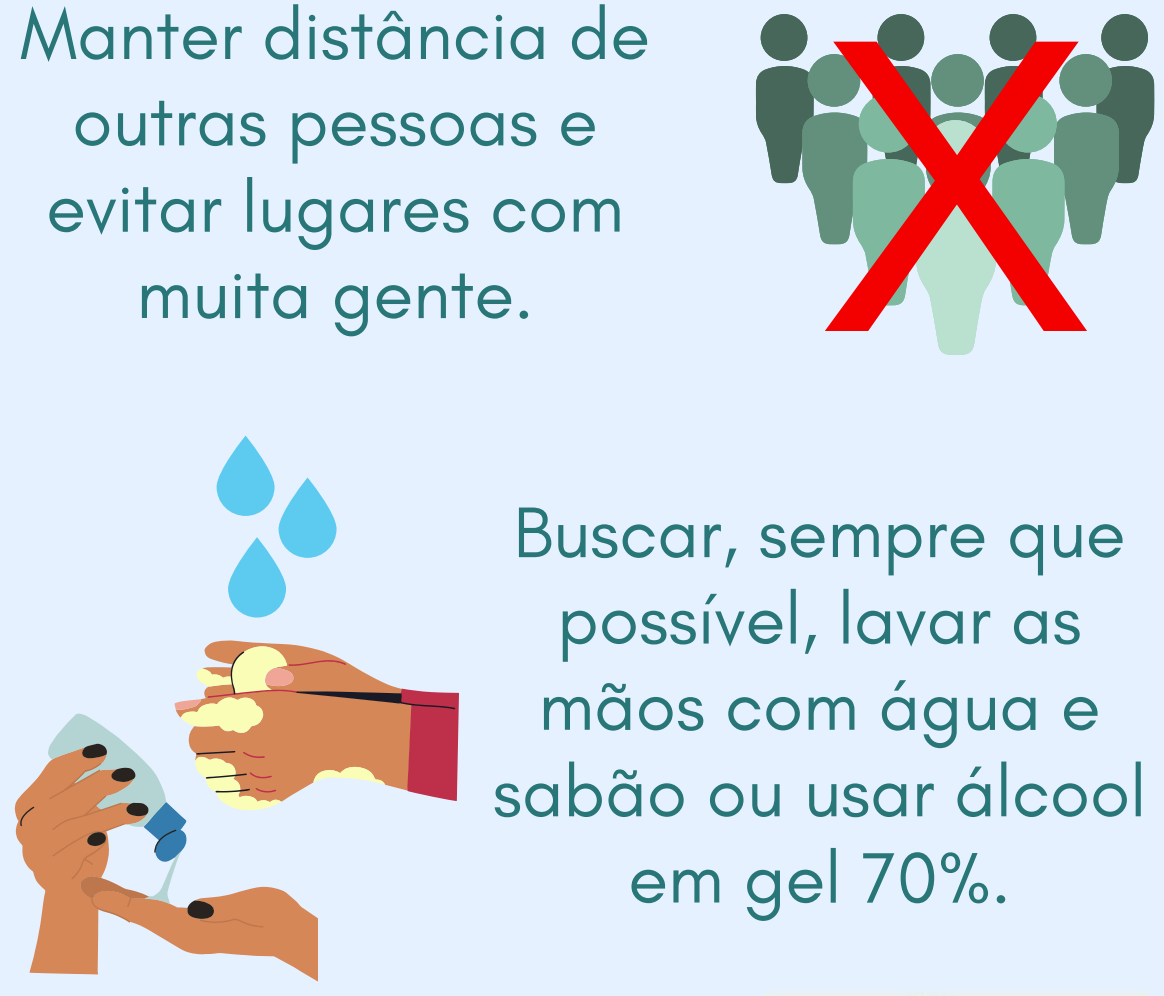

Buscar, sempre que possível, lavar as mãos com água e sabão ou usar álcool em gel $70 \%$.

\section{Quando tossir ou} espirrar, cobrir o rosto com a parte de dentro do cotovelo ou antebraço.

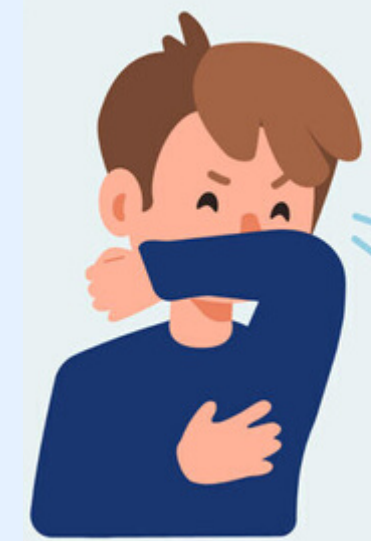




\section{COMO SE PREVENIR?}

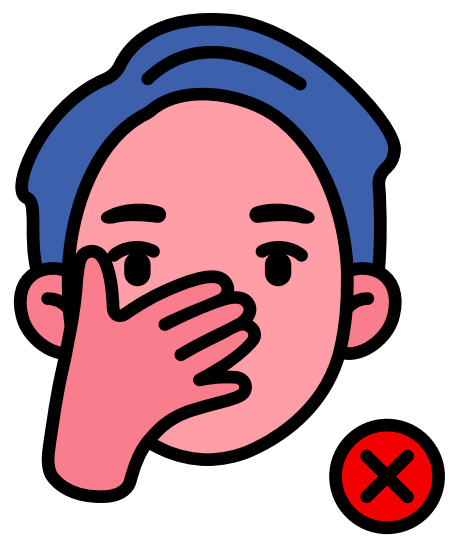

\section{Evitar tocar os olhos, o nariz ou a boca.}

Quando ficar em abrigos ou albergues, não esquecer de manter distância de outras pessoas, não compartilhar objetos (garrafas, copos, talheres, etc.) e manter sempre o local ventilado.
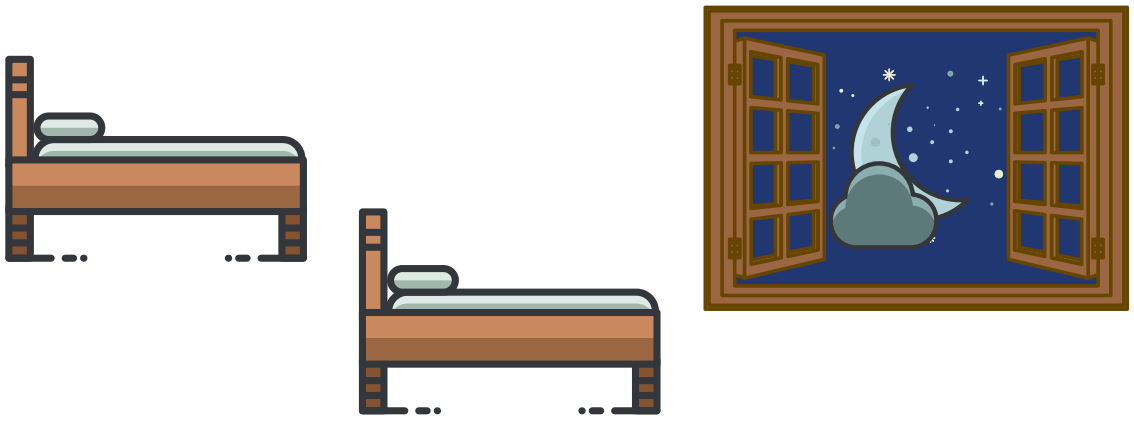


\section{COMO SE PREVENIR?}

Em filas de distribuição de comida ou abrigos, manter distância de pelo menos 4 passos simples $(1,5 \mathrm{~m})$ de outras pessoas
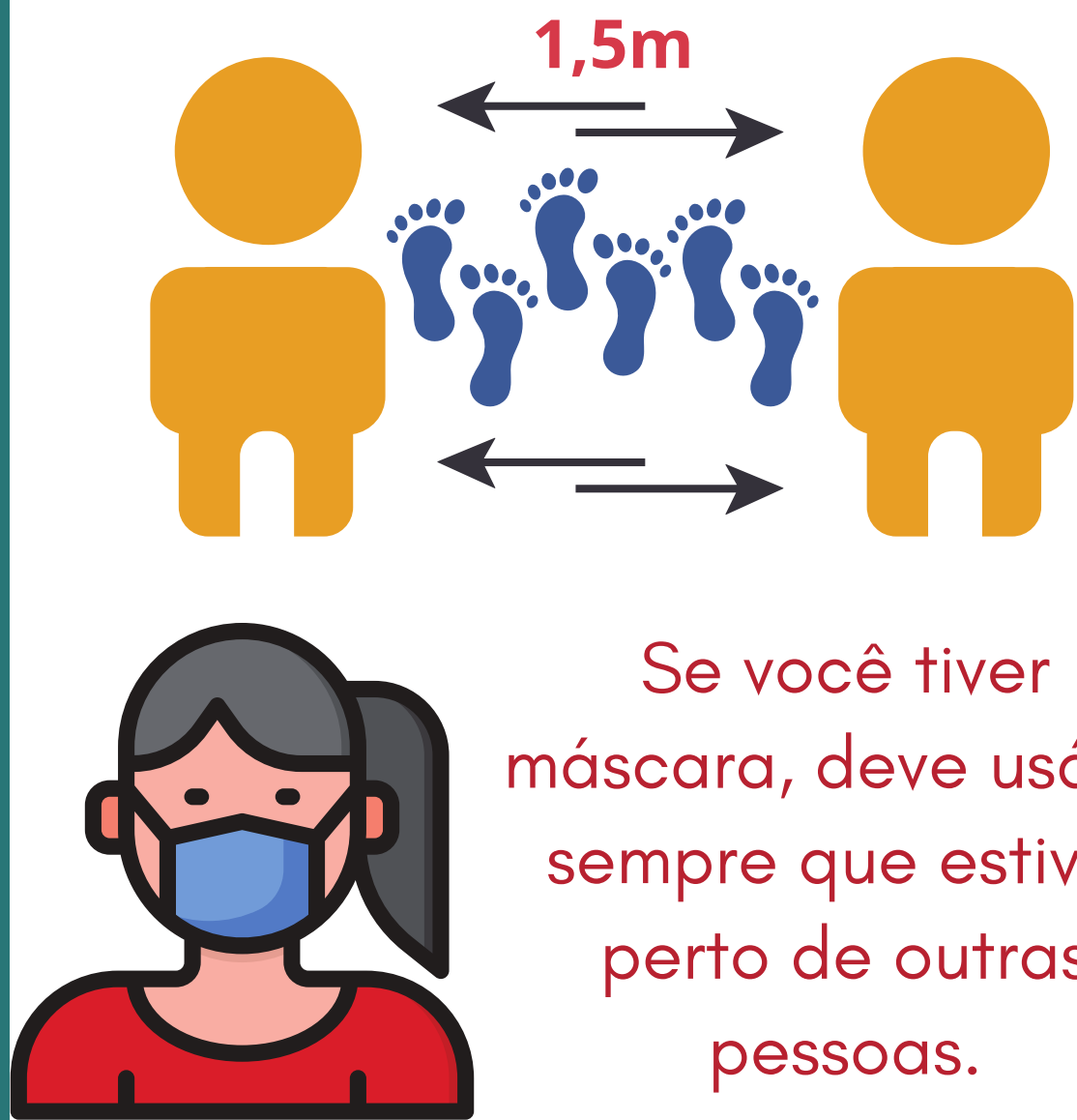

\section{Se você tiver}

máscara, deve usá-la sempre que estiver

perto de outras pessoas. 


\section{COMO SE PREVENIR?}

\section{CUIDADOS COM A MÁSCARA:}

Quando for retirá-la, tocar somente nas alças laterais.

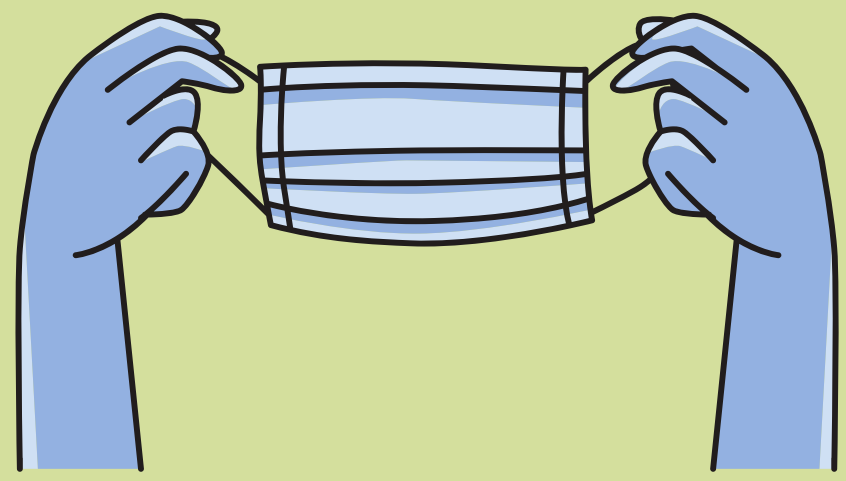

Trocar a máscara sempre que perceber que ela está úmida.

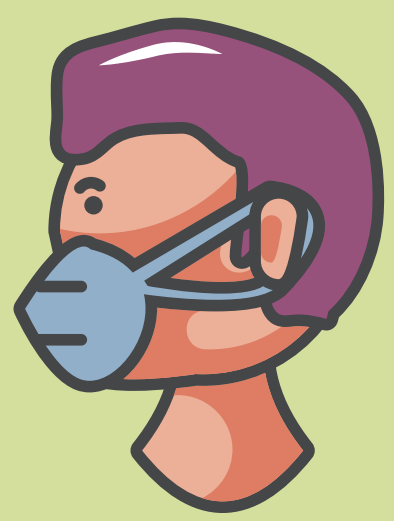




\section{COMO SE PREVENIR?}

Sempre que possível ou necessário, ter materiais como máscaras, álcool em gel, sabão e sabonete.
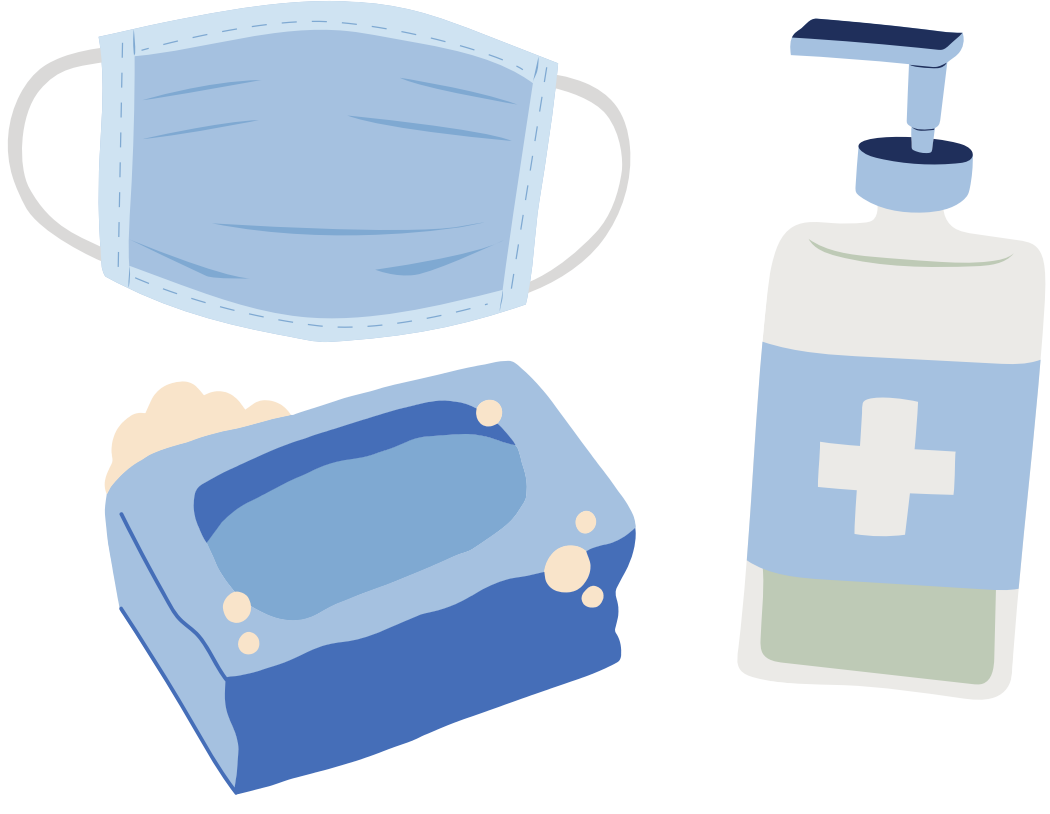

Geralmente, eles são oferecidos pelas Prefeituras, ONGs e projetos sociais. 

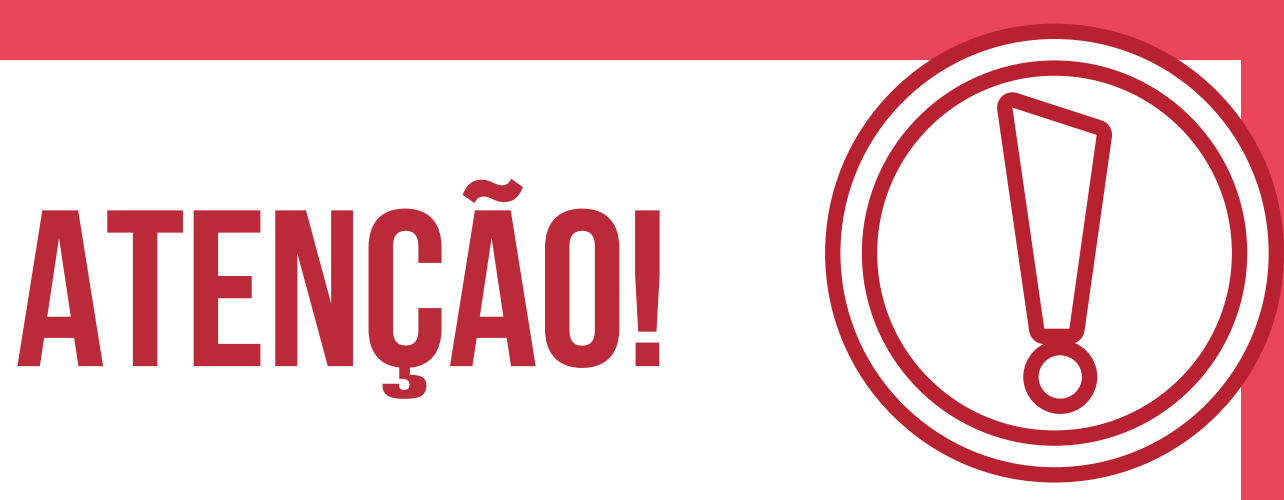

Não esquecer de frequentar 0 postinho de saúde para manter em dia suas vacinas e demais consultas, para não lotar hospitais e unidades de saúde com outras doenças além

\section{da COVID-19.}


Ainda não há vacina

nem medicamento para cura da COVID-19.

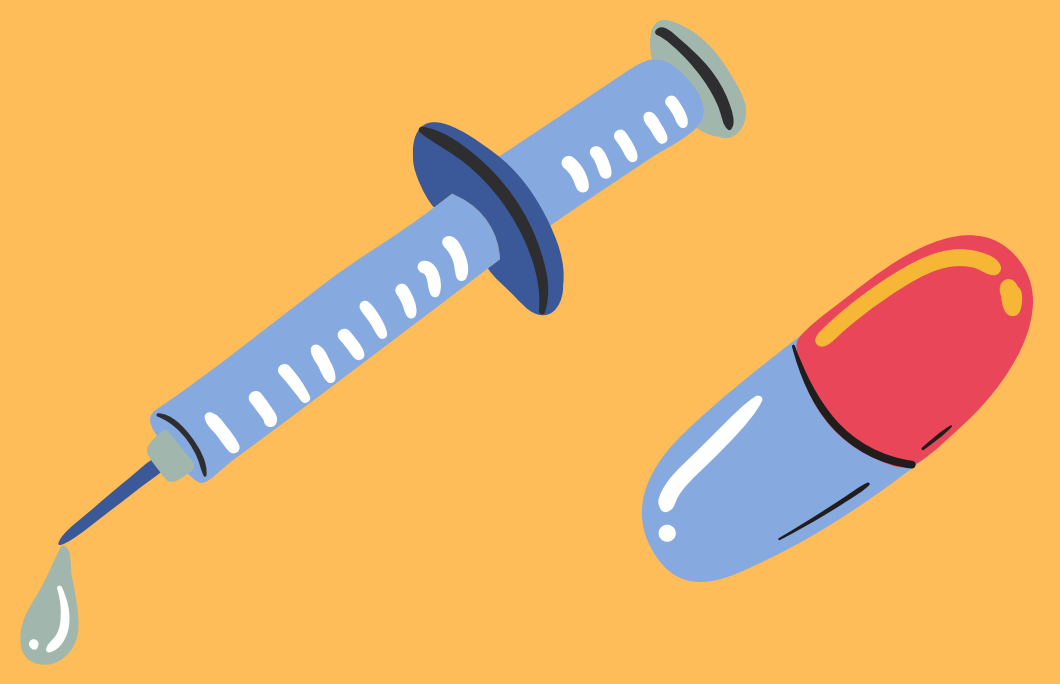

PRECISAMOS

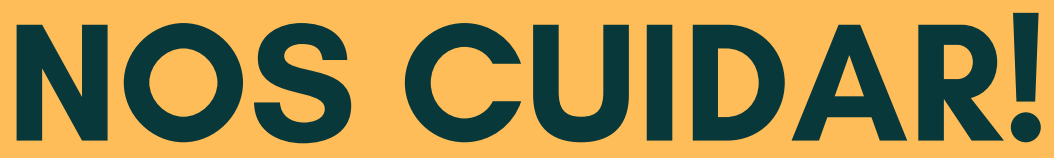




\section{ONDE BUSCAR APOIO?}

Existem vários espaços onde há pessoas para auxiliar e dar apoio neste momento de combate

$$
\text { à COVID-19. }
$$

A seguir, apresentamos alguns desses espaços e também outros contatos que podem oferecer mais informações!

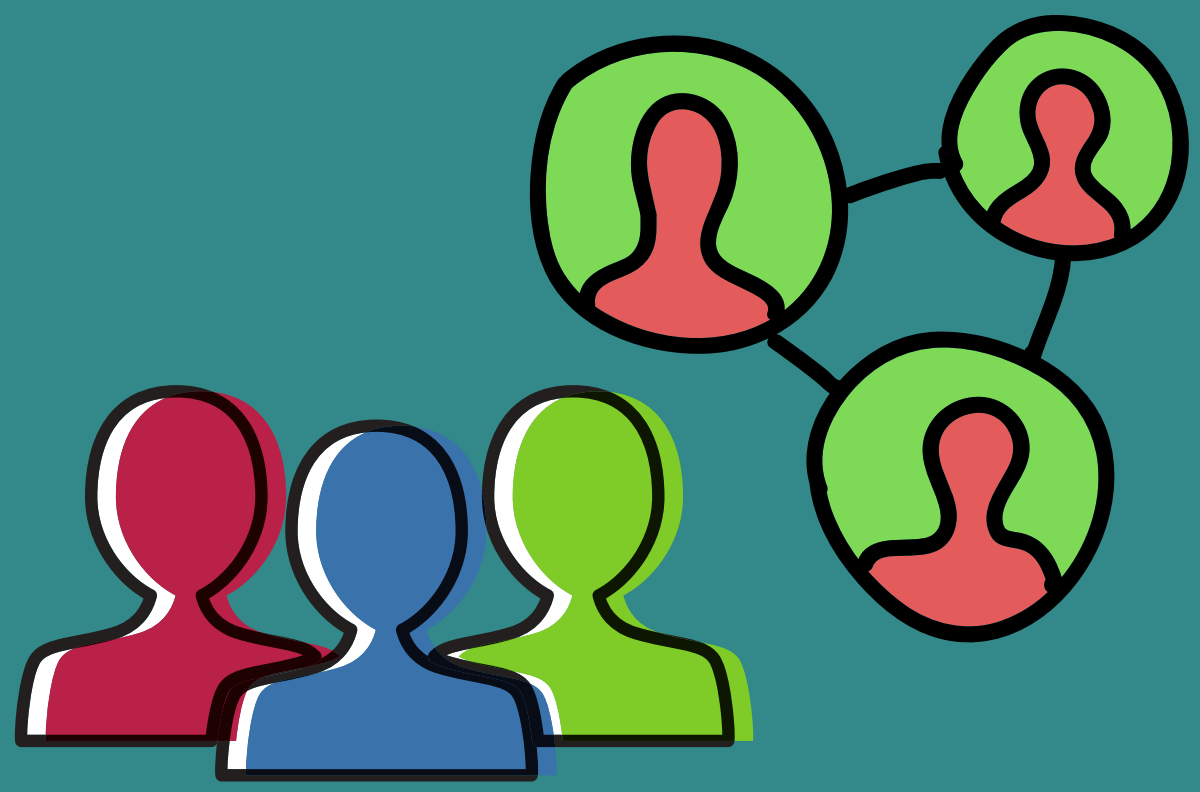




\section{CENTRO POP}

$\mathrm{O}$ Centro POP atende à população em situação de rua, com espaços para guarda de pertences, realização de higiene pessoal, auxílio com a documentação pessoal e distribuição de alimentos.

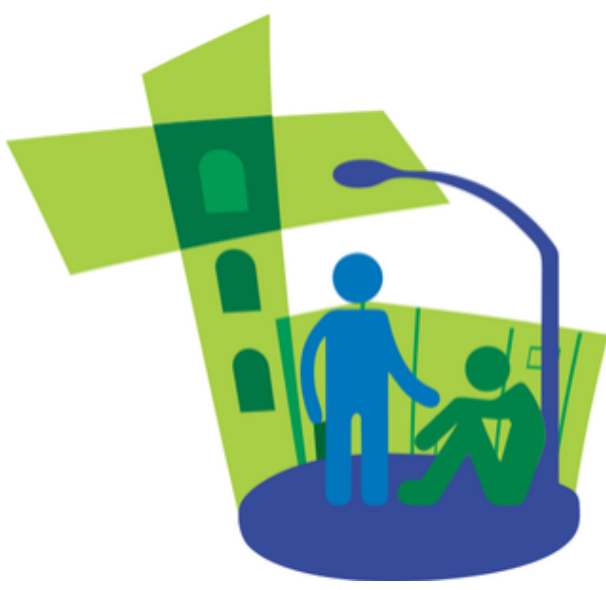

C E N T R
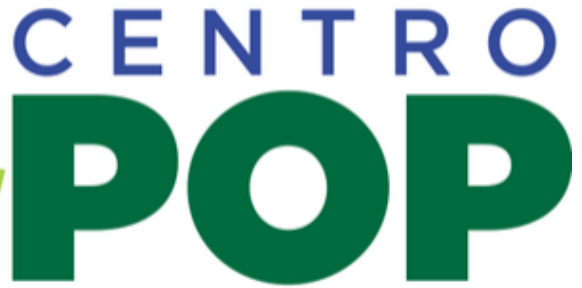

Centro de Referência Especializado para População de Rua 


\section{OS CENTROS DE REFERÊNCIA DE}

\section{ASSISTÊNCIA SOCIAL (CRAS) E OS}

CENTROS DE REFERÊNCIA ESPECIALIZADOS

DE ASSISTÊNCIA SOCIAL (CREAS)

São locais que oferecem orientação, proteção e acompanhamento às famílias com um ou mais membros em situação de risco pessoal e social, ameaça ou violação de direitos. Contando com diferentes profissionais, o CREAS desenvolve ações para fortalecer vínculos familiares, comunitários e sociais, procurando reduzir as vulnerabilidades e as situações de risco vivenciadas pela população.
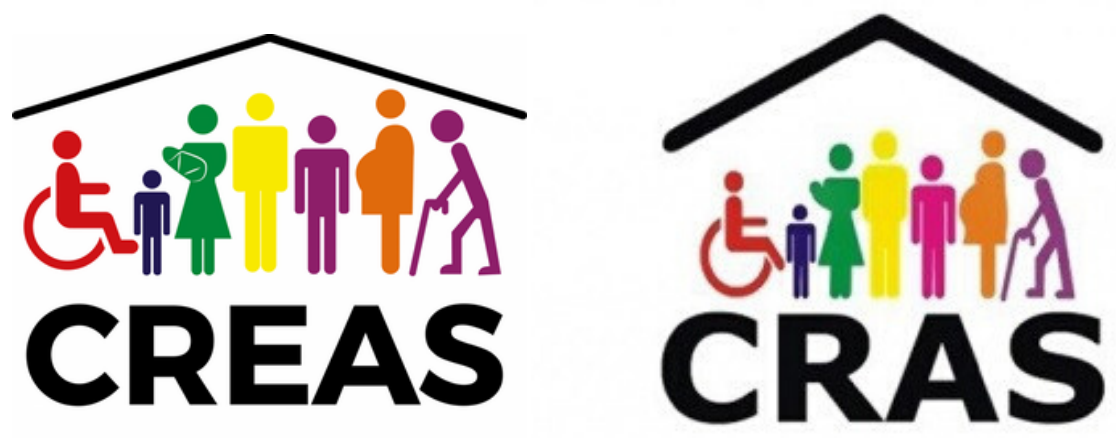


\section{ONGs}

As Organizações

Não-Governamentais (ONGs)

incluem associações e

movimentos populares voltados a proteger a população em situação de rua.
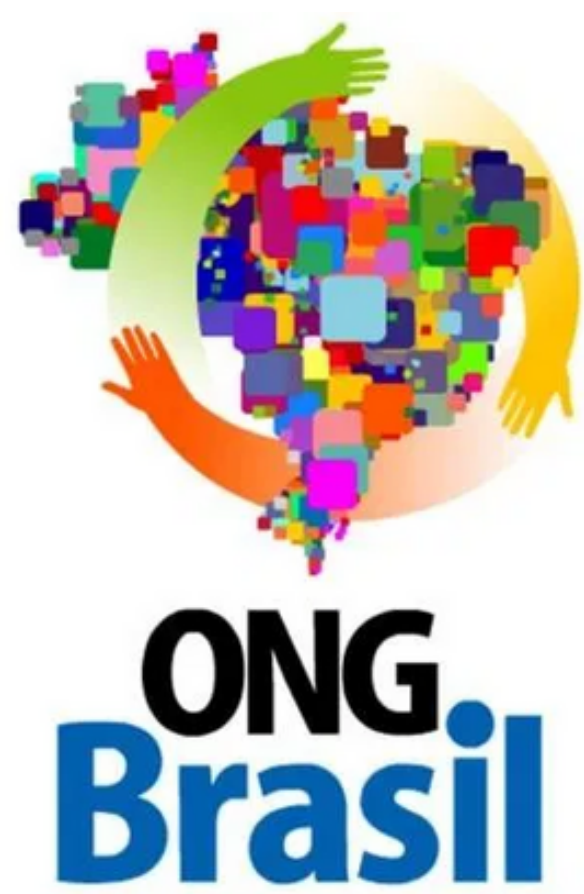


\section{BUSOUE ATENDIMENTO}

\section{E SE INFORME!}

Deixamos alguns telefones para que você possa ter mais informações sobre a COVID-19 em seu município!

CALL CENTER PARANÁ $0800-6444414$

ou

(41) $99117-3500$
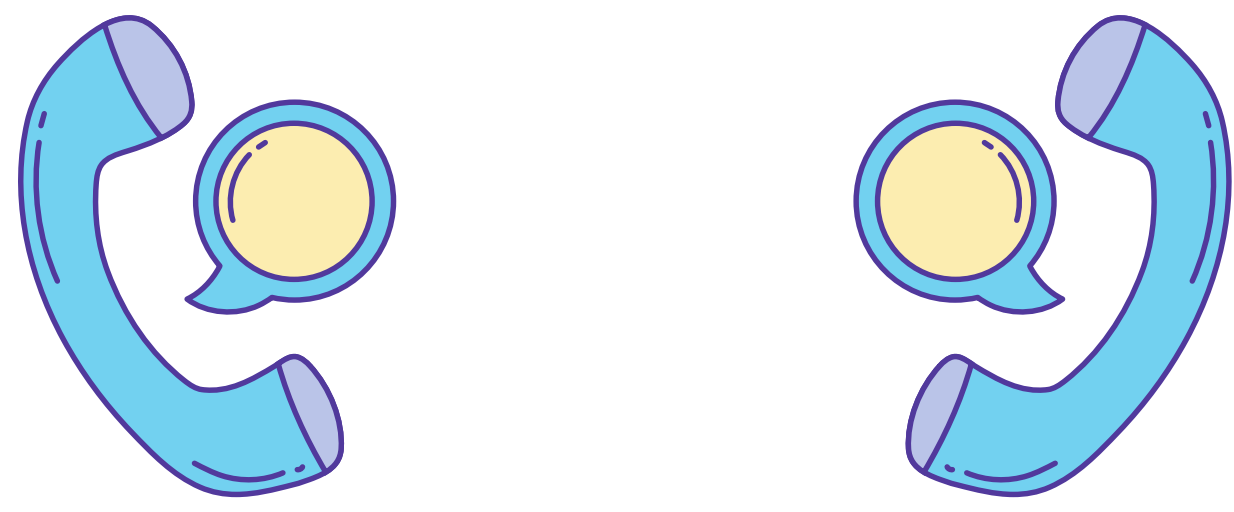


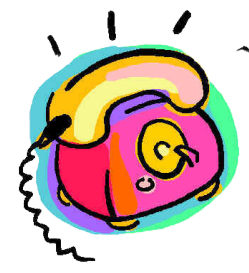

AGUDOS DO SUL

(41) 3674-1034

(41) 99256- 2041

ARAUCÁRIA

0800-6425250

CAMPINA GRANDE DO SUL

(41) 3676-8160

(41) $99122-8142$

CAMPO DO TENENTE

(41) 3628-1686

(41) $98809-3808$

CAMPO LARGO

(41) 3291-5125

CAMPO MAGRO

(41) 3677-5588

(41) 36772368

(41) $98409-5577$

(41) 98409-8812

CURITIBA

(41) $99876-2903$ 


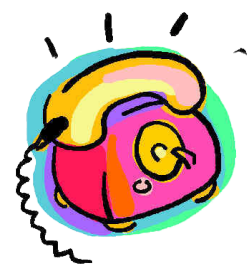

\section{MANDIRITUBA}

(41) $99142-9775$

(41) $99118-7042$

PIÊN

(41) 3632-1378

(41) $99672-0339$

PINHAIS

(41) 98814-6838

(41) $98742-6383$

PIRAQUARA

(41) 3590-3722

(41) $3590-3763$

QUATRO BARRAS

(41) 99224-6109

RIO BRANCO DO SUL

(41) 3603-1097

SÃO JOSÉ DOS PINHAIS

(41) 3381-6388

(41) 98508-0364

TUNAS DO PARANÁ

(41) 98772-2746 


\section{CASO EU NÃO TENHA}

ACESSO A SERVIÇOS OU

APOIO, ONDE POSSO

BUSCAR MEUS DIREITOS?

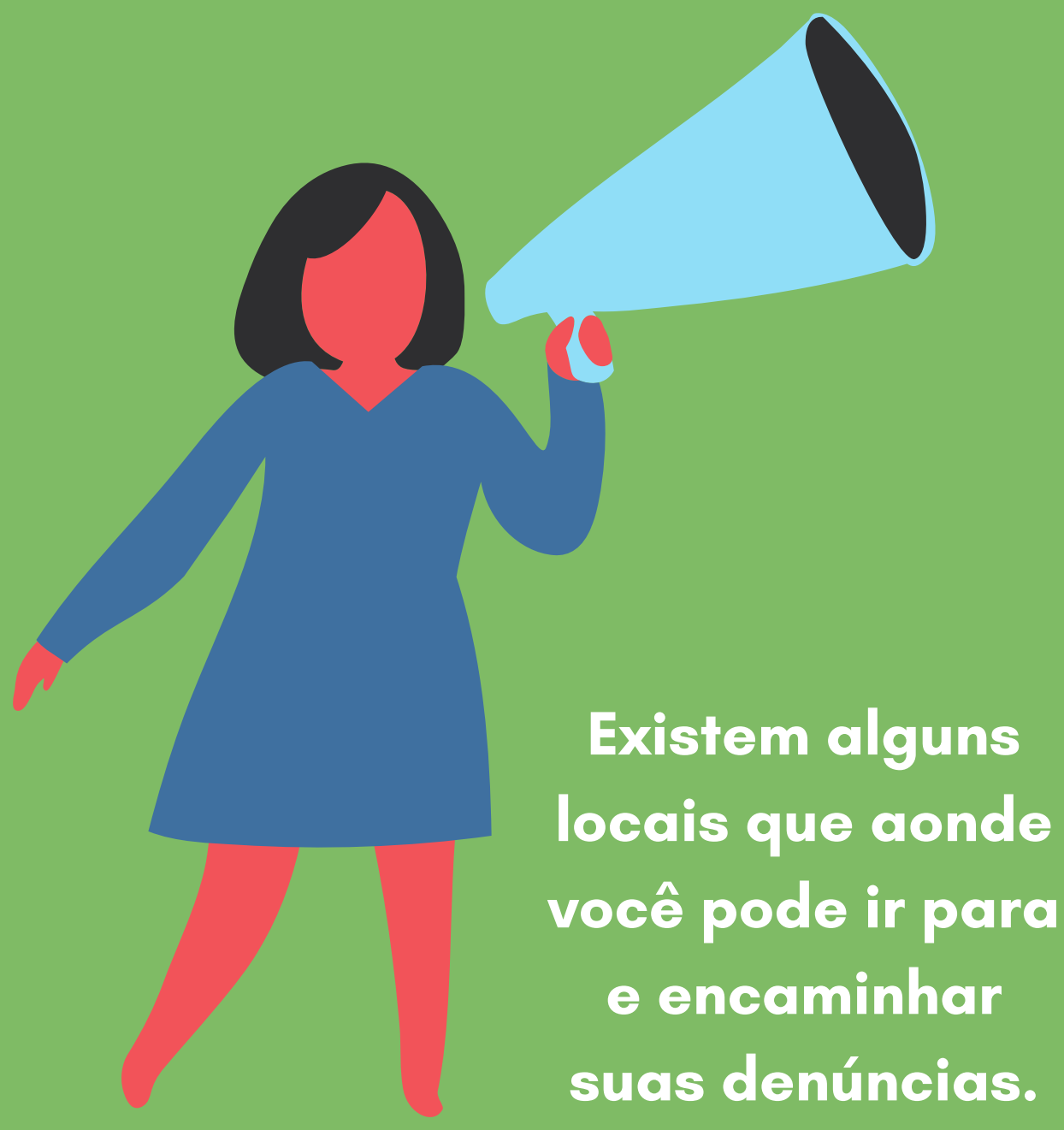




\section{CONSELHOS}

\section{MUNICIPAIS DE SAÚDE}

Os Conselhos de Saúde reúnem pessoas para fiscalizar os serviços de saúde e cobrar que funcionem direito!

Metade dos participantes dos conselhos é formada por usuários do SUS, como nós! Os conselhos e conselheiros recebem denúncias sobre as dificuldades que encontramos em nossa saúde. Para ter acesso aos contatos dos vários conselhos de saúde dos municípios da Segunda Regional de Saúde, acesse o link $<$ https://bit.ly/2SKajug>

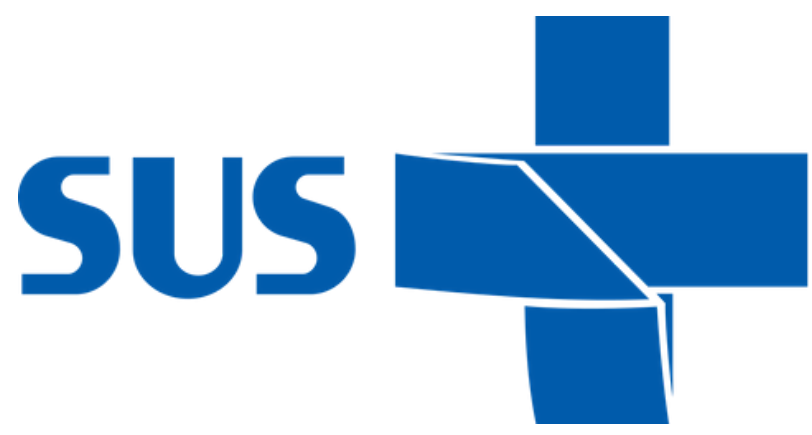




\section{OUVIDORIA}

Esse serviço recebe e analisa reclamações, sugestões e denúncias, encaminhando-as para os órgãos competentes. É papel da ouvidoria acompanhar sua denúncia e mantê-lo informado sobre os encaminhamentos para resolver sua queixa.

Para ter acesso ao contato da ouvidoria dos municípios da Segunda Regional de Saúde, acesse $\mathrm{o}$ link <https://bit.ly/2SKajug>

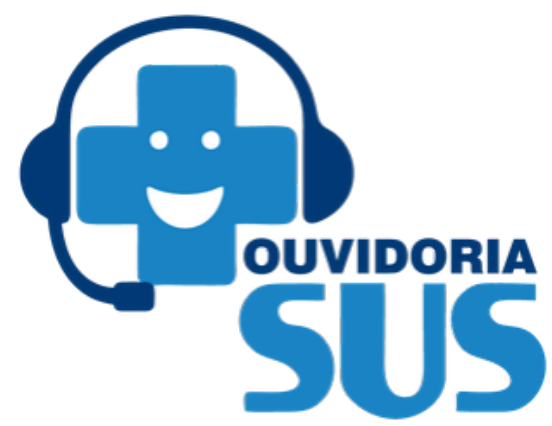

\section{DISQUE SAÚDE}

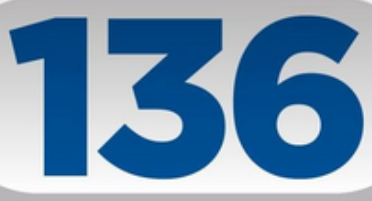

Ouvidoria Geral do SUS. www.saude.gov.br 


\section{MINISTÉRIO PÚBLICO}

O Ministério Público (MP) é o advogado da sociedade, para garantir que seus direitos sejam cumpridos. O MP é uma instituição pública e tem como objetivo

a defesa dos interesses sociais e coletivos, entre eles o direito à saúde.

O contato com o MP pode ser feito pelos seguintes canais: Telefone: (41) 41 3250-4000 Site: <http://www.mp.pr.gov.br> E-mail: saudemp@mp.pr.gov.brou caop.direitoshumanos@mppr.mp.br

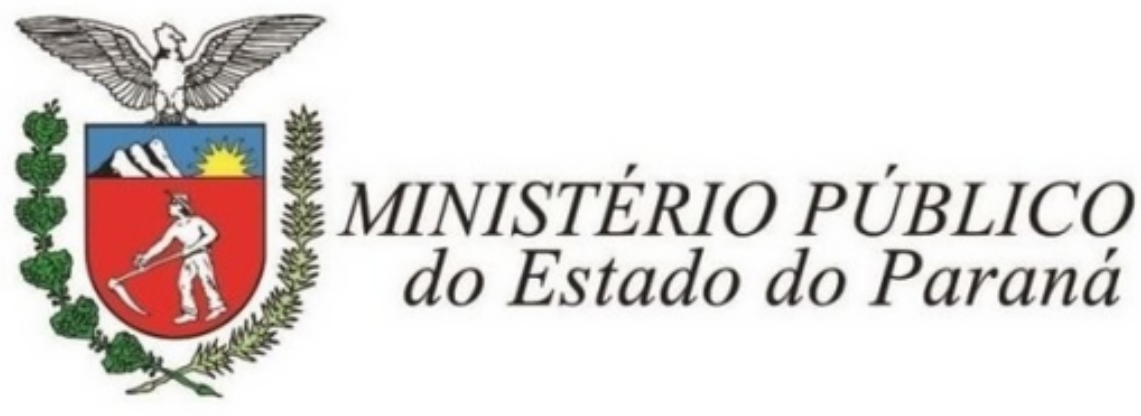




\section{DEFENSORIA PÚBLICA DO PARANÁ}

A Defensoria Pública presta assistência jurídica gratuita àqueles que não têm condições de pagar um advogado e as despesas de um processo judicial. Por conta da pandemia do coronavírus, a defensoria somente fará atendimentos urgentes, exclusivamente das $12 \mathrm{~h}$ às 17h e pelos canais a seguir:

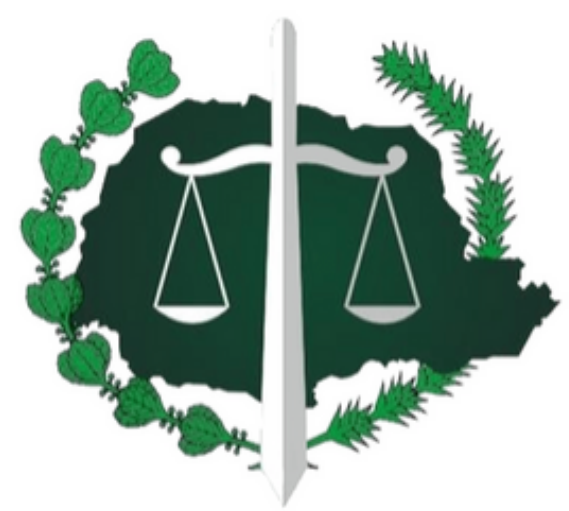

Defensoria Pública do Estado do Paraná 


\section{DEFENSORIA PÚBLICA DO PARANÁ}

Cível e Fazenda Pública (acompanhamento):

(41) 9 9124-3678

Execução Penal:

(41) 9 9155-9047

Família (inicial):

(41) 9 8400-8167

Família (acompanhamento):

(41) 9 9561-9203

Centro de Atendimento

Multidisciplinar:

(41) 9 9188-3726 


\section{ÓRGÃOS DE DEFESA DOS DIREITOS HUMANOS}

São órgãos do governo que recebem denúncias sobre violações dos direitos humanos. Quando a denúncia é recebida, ocorre uma investigação dos fatos.

Existem Comissões de Direitos Humanos ligadas à Câmara dos Deputados, Assembleias Legislativas e Câmaras Municipais, além de Secretarias, Conselhos de Direitos Humanos, Prefeituras, Governos Estaduais e Presidência da República.

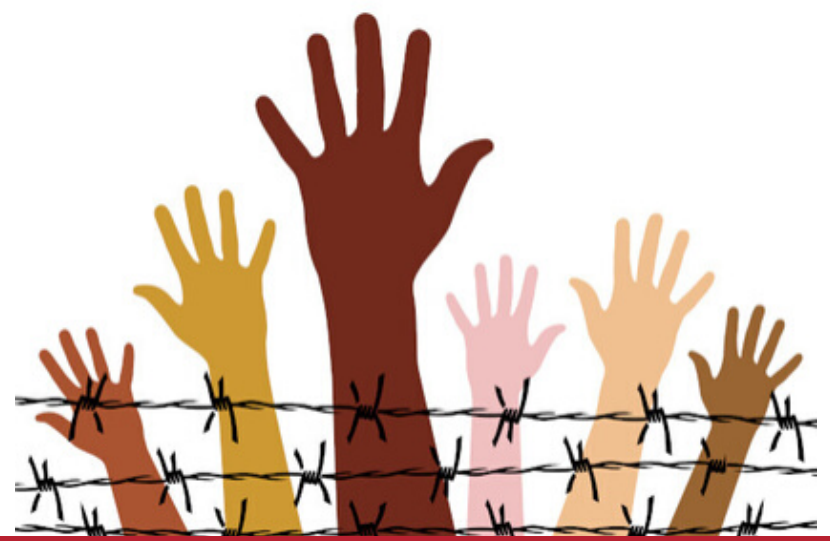




\section{MOVIMENTO NACIONAL DA POPULAÇÃO DE RUA}

Surgiu para enfrentar os riscos da vida na rua e para repudiar o preconceito, a discriminação, as violações dos direitos humanos, bem como reivindicar políticas públicas que atendam às necessidades e à dignidade humana.

<https://www.facebook.com/MNPRSP/>

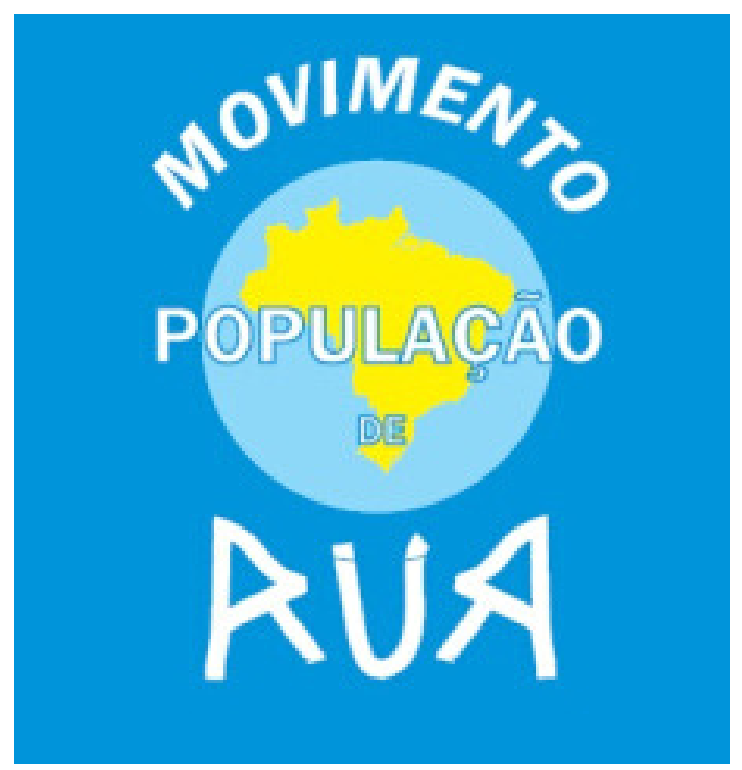




\section{ASSOCIAÇÃO \\ ARNALDO GILBERTI}

A Associação Arnaldo Gilberti (AAG) é uma associação de Curitiba voltada a proteger os direitos humanos da população. A AAG recebe denúncias, assessora o denunciante e encaminha e acompanha as queixas para os órgãos competentes. Como ela, existem várias

ONGs nas quais pessoas de nossa comunidade podem te ajudar!

Clique em "denuncie". $<$ www.arnaldogilberti.org>

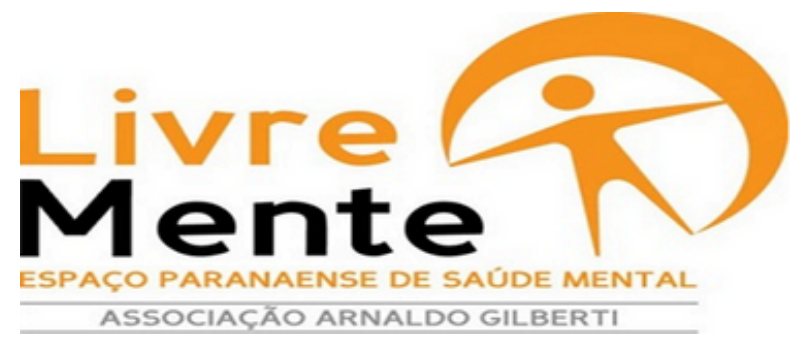




\section{DISQUE}

Existem vários telefones

importantes, disponibilizados

pelo poder público e entidades

sociais para a realização de denúncias e solicitação de informações.

Disque Direitos Humanos - 100

Disque Violência contra a Mulher - 180

Disque Denúncia - 181
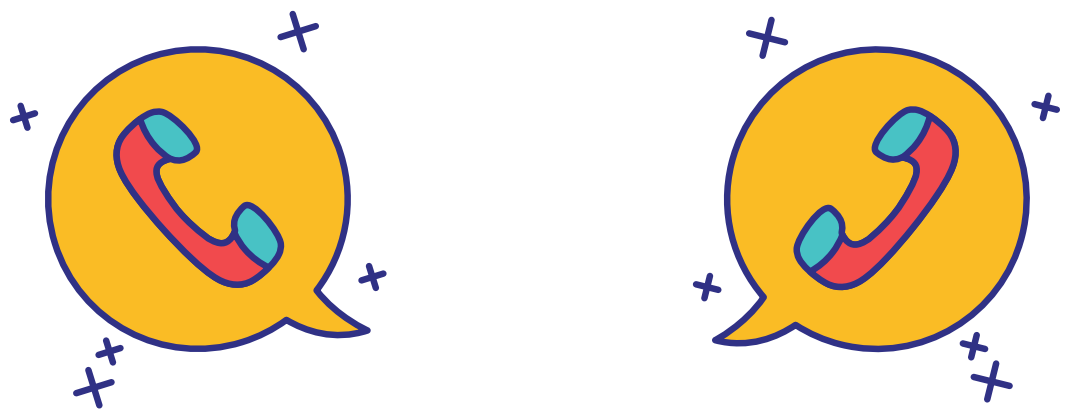


\title{
CASO VOCÊ PRECISE DE MAIS INFORMAÇÕES
}

Disponibilizamos uma lista com vários serviços de saúde, assistência social, defesa dos direitos humanos e ONGs

localizados nos municípios da $2^{a}$ Regional de Saúde que podem ajudar neste e em outros momentos!

\author{
Acesse o link abaixo! \\ $<$ https://bit.ly/2SKajug>
}




\section{REFERÊNCIAS}

BRASIL. Ministério da Cidadania. Apresentação: Centro de Referência Especializada Para Pessoas em Situação de Rua Centro Pop. Disponível em: <http://aplicacoes.mds.gov.br/ sagi/publicacao_eletronica/censo2011/pop.html>. Acesso em: 28 maio 2020.

BRASIL. Ministério da Cidadania. Apresentação: Centro de Referência de Assistência Social (CRAS). Disponível em: <http://aplicacoes.mds.gov.br/sagi/publicacao_eletronica/ce nso2011/cras.html>. Acesso em: 28 maio 2020.

BRASIL. Ministério da Cidadania. Apresentação: Conselho Municipal de Assistência Social (CMAS). Disponível em: <http://aplicacoes.mds.gov.br/sagi/publicacao_eletronica/ce nso2011/conselho-municipal.html>. Acesso em: 28 maio 2020.

BRASIL. Ministério da Cidadania. Centro de Referência Especializada Para Pessoas em Situação de Rua Centro Pop. 2015. Disponível em: <http://mds.gov.br/assuntos/assi stencia-social/unidades-de-atendimento/centro-pop>. Acesso em: 28 maio 2020.

BRASIL. Ministério da Cidadania. Apresentação: Centros de Referência Especializados de Assistência Social (CREAS). Disponível em : <http://aplicacoes.mds.gov.br/sagi/publica cao_eletronica/censo2011/creas.html>. Acesso em: 28 maio 2020. 
BRASIL. Ministério da Saúde. Cartilha de informações coronavírus. 2020. Disponível em: <https://www.saude.go v.br/images/pdf/2020/April/07/Cartilha-Coronavirus-Inform acoes>. Acesso em: 28 maio 2020.

BRASIL. Ministério da Saúde. Coronavírus: 43.079 casos e 2.741 mortes. 2020. Grupos de risco. Disponível em: <https://www.saude.gov.br/noticias/agencia-saude/46764coronavirus-43-079-casos-e-2-741-mortes>. Acesso em: 28 maio 2020.

BRASIL. Ministério da Saúde. Coronavírus: O que você precisa saber. Quais são os sintomas. Disponível em: <https://coronavirus.saude.g ov.br/>. Acesso em: 28 maio 2020.

FUNDAÇÃO DE AÇÃO SOCIAL (FAS). Centro Pop: Centro de Referência Especializada Para Pessoas em Situação de Rua. Unidades Pop para jovens e adultos em Curitiba. Disponível em: <https://fas.curitiba.pr.gov.br/conteudo.aspxidf=211..>. Acesso em: 28 maio 2020.

FUNDAÇÃO DE AÇÃO SOCIAL (FAS). Endereços dos Centro de Referência da Assistência Social, Unidade de Atendimento e Centro de Atividades para Idosos.

Disponível em: <https://fas.curitiba.pr.gov.br/conteudo.asp x?idf=75>. Acesso em: 28 maio 2020.

FUNDAÇÃO DE AÇÃO SOCIAL (FAS). Endereço dos Centros de Referência Especializados da Assistência Social. Disponível em: <https://fas.curitiba.pr.gov.br/conteudo.asp x?idf=89> . Acesso em: 28 maio 2020. 
Instituto Nacional do Câncer (INCA). Quem fuma faz parte do grupo de risco para o Coronavírus (Covid-19). 2020.

Disponível em: <https://www.inca.gov.br/perguntasfrequentes/quem-fuma-faz-parte-do-grupo-de-risco-para-ocoronavirus-covid-19>. Acesso em: 28 maio 2020.

OPAS Brasil. Folha informativa: COVID-19 (doença causada pelo novo coronavírus). 2020. Disponível em: <https://www. paho.org/bra/index.php?option=com_content\&view=article \&id=6101: covid19\&ltemid=875>. Acesso em: 28 maio 2020.

PARANÁ. Ministério Público. Conheça o MPPR: Sobre a Instituição. Disponível em: <http://www.mppr.mp.br/modul es/conteudo/conteudo.php?conteudo=44\#>. Acesso em: 28 maio 2020.

RAVAGNANI, H.; RAMOS, P. S. Sintomas do Corona Virus. In: COSTA, Camila. Coronavírus: como diferenciar sintomas da covid-19 de uma gripe, um resfriado ou uma rinite?. BBC News Brasil, 19 março 2020. Disponível em:

<https://www.bbc.com/portuguese/brasil-51946693>. Acesso em: 28 maio 2020.

\section{URBANISTAS CONTRA CORONA. Cartilha de orientação} para população em situação de rua e iniciativas sociais para prevenção ao coronavírus. 2020. Disponível em: <https://drive.google.com/file/d/172UKItdyZPALyT4HRq1_Ct3gKorTolq/view?usp=sharing>. Acesso em: 28 maio 2020. 